\title{
Lack of QT Prolongation for 2'-O-Methoxyethyl-Modified Antisense Oligonucleotides Based on Retrospective Exposure/Response Analysis of Ten Phase 1 Dose-Escalation Placebo-Controlled Studies in Healthy Subjects
}

\author{
Rosie Z. Yu, Rudy Gunawan,' Richard S. Geary, Steven G. Hughes,2 Scott P. Henry, and Yanfeng Wang ${ }^{1}$
}

\begin{abstract}
The potential of QT prolongation of ten 2'-O-methoxyethyl-modified (2'-MOE) antisense oligonucleotides (ASOs) was evaluated retrospectively via exposure/response (ER) analysis using data from Phase 1 clinical studies in healthy subjects. All Phase 1 studies were double-blind, placebo-controlled, single and multiple ascending dose studies designed to assess the safety, tolerability, pharmacokinetics (PK), and pharmacodynamics of the ASOs in healthy subjects. The active doses in these studies ranged from 50 to $450 \mathrm{mg}$ administered by subcutaneous (SC) injection in single and multiple ascending dose cohorts. Two of the ten studies also included 2-h intravenous (IV) infusions up to $600 \mathrm{mg}$. Electrocardiogram (ECG) measurements were performed at baseline and selected time points (including $\left.T_{\max }\right)$. The correlation between QTcF intervals corrected for baseline ( $\triangle \mathrm{QTcF}$ ) and the mean timematched placebo $(\Delta \Delta \mathrm{QTCF})$ with $\mathrm{PK}$ plasma exposure when available was evaluated using a linear mixed-effects approach. There was no evidence for QTc prolongation associated with increasing plasma concentrations in healthy subjects, including exposures with treatment up to $450 \mathrm{mg}$ administered SC or $600 \mathrm{mg}$ by IV infusions, and concentrations that are 4-20 times the $C_{\max }$ of the therapeutic dose, as assessed by both $\Delta \mathrm{QTcF}$ and $\Delta \Delta \mathrm{QTcF}$. The ER analysis of the relationship between drug plasma concentration and $\Delta \Delta \mathrm{QTcF}$ showed that the slope of the regression line was close to zero, and the upper bound of the $90 \%$ confidence interval at twice the mean observed (or predicted) $C_{\max }\left(2 \times C_{\max }\right)$ of the clinical therapeutic dose (ie, the highest clinically relevant plasma concentration) was well below $10 \mathrm{~ms}$ for all 10 compounds evaluated. Therefore, no concentration-dependent effect on QT prolongation was observed for any one of the ten $2^{\prime}$-MOE ASOs evaluated in Phase 1 studies. These results confirmed that 2'-MOE ASOs, as a chemical class, do not cause QT prolongation at clinically relevant dose levels.
\end{abstract}

Keywords: antisense, oligonucleotide, QT prolongation

\section{Introduction}

A NTISENSE OLIGONUCLEOTIDES (ASOs) are short, chemically modified, synthetic, single-strand DNA/RNA-like oligonucleotides (typically 14-22 nucleotides in length) that have the ability to target a gene product of interest by specifically hybridizing with the target complementary mRNA via sequence-specific Watson-Crick base pairing. The targeted mRNA may be modulated by several mechanisms, including degradation by $\mathrm{RNase} \mathrm{H} 1$, or by redirecting posttranscriptional splicing processes [1,2], and ultimately, regulating target protein biosynthesis.
As a platform of therapeutics, $2^{\prime}$ - $O$-methoxyethyl $\left(2^{\prime}\right.$ MOE)-modified ASOs have unique physicochemical properties, which differentiate them from small-molecule drugs and large protein drugs, in that ASOs are hydrophilic, highly water soluble, and polyanionic, with molecular weight in the range of 6,000-8,000 Da. The pharmacokinetics (PK) of 2'MOE ASOs are remarkably similar across sequence and animal species, which makes their PK in humans highly predictable [3-6]. Following subcutaneous (SC) administration, $2^{\prime}$-MOE ASOs are rapidly absorbed into the systemic circulation, with peak plasma levels observed within a few hours after dosing. After reaching $C_{\max }$, plasma concentrations

\footnotetext{
Departments of ${ }^{1}$ Pharmacokinetics and Clinical Pharmacology, ${ }^{2}$ Clinical Development and ${ }^{3}$ Nonclinical Development, Ionis Pharmaceuticals, Inc., Carlsbad, California.

(c) Rosie Z. Yu et al. 2017; Published by Mary Ann Liebert, Inc. This article is available under the Creative Commons License CC-BY-NC (http://creativecommons.org/licenses/by-nc/4.0). This license permits non-commercial use, distribution and reproduction in any medium, provided the original work is properly cited. Permission only needs to be obtained for commercial use and can be done via RightsLink.
} 
decline in a multiphasic manner with an initial, relatively fast disposition phase that dominated the plasma clearance followed by a slower elimination phase, with apparent terminal elimination half-life of 2-4 weeks. Plasma $C_{\max }$ and area under curve (AUC) were dose dependent over the studied SC dose range with low to modest intersubject variability. Mean plasma concentrations decreased $>90 \%$ from the $C_{\max }$ by $24 \mathrm{~h}$ after $\mathrm{SC}$ injections. Attributed to this initial rapid and nearly complete distribution phase, there was no accumulation at $C_{\max }$ or AUC after repeated SC doses, although having exhibited long terminal elimination half-lives. ASOs in this chemical class are highly bound to plasma proteins ( $>95 \%$ in man) and are broadly distributed to many tissues following parenteral administrations with the highest accumulation in the kidney and liver, but poorly distributed to skeletal muscle and heart, and do not cross the blood-brain barrier [6-8].

ASOs in this chemical class (2'-MOE-modified ASOs) are metabolized by ubiquitous nucleases and have not been reported to be substrates, inhibitors, or inducers of cytochrome P450 enzymes in vitro or in vivo, and thus are not expected to interact with small molecules that are predominately cleared through oxidative metabolic pathways [9]. In addition, 2'MOE-modified ASOs are not substrates or inhibitors of uptake or efflux membrane transporters (eg, OATP, OAT, and MDR1), some of which transporters can be involved in the absorption, disposition, and excretion of certain drugs [10]. Several clinical studies have examined the PK drug-drug interaction potential of $2^{\prime}$-MOE-modified ASOs with a number of small-molecule drugs and antineoplastic agents, and no metabolic based drug-drug interactions have been observed to date $[9,11]$.

2'-O-methoxyethyl-modified ASOs have demonstrated a lack of inhibition of human ether-a-go-go-related gene (hERG) channel current and no effect on cardiovascular function has been reported in both hERG assay and animal telemetry studies, suggesting a lack of interaction with extracellular or intracellular domains of the hERG channel, apparently due to their large molecular size and multiple negative charges [12]. No clinically significant QT prolongation related to 2'-MOE ASOs has also been observed in the clinic. A recent publication on custirsen, a 4-13-4 2'-MOE gapmer ASO, showed no effect on QT intervals based on PK/QT data in a Phase 1 dose-escalation study with dose up to $640 \mathrm{mg}$ administered via 2 -h intravenous (IV) infusion and plasma concentrations up to $90 \mu \mathrm{g} / \mathrm{mL}$ [13]. In addition, lack of QT effects of another 2'-MOE ASO, mipo- mersen, was demonstrated in both a Phase 1 dose-escalation study and a formal thorough QT (TQT) study [13]. Furthermore, studies with mipomersen showed that the exposure/response (ER) correlation analyses in the Phase 1 dose-escalation study and the TQT study are in good agreement, suggesting that the ER analysis in Phase 1 dose-escalation studies for 2'-MOE gapmer ASOs can be predictive of QT effect, as expected from a TQT study [14]. This finding is consistent with recent studies showing that TQT studies can be replaced with the ER analysis of the relationship between plasma drug concentration and $\Delta \Delta \mathrm{QTcF}$ from Phase 1 dose-escalation studies $[15,16]$ and the recently published ICH Final Concept Paper E14 [17].

Based on the similarities of $2^{\prime}$-MOE ASOs in terms of physicochemical properties, PK, and a lack of effect on hERG channel or QT prolongation in animal models, and the findings of the lack of effect on QT intervals in the clinic reported for two 2'-MOE ASOs, it is unlikely that other $2^{\prime}$ MOE ASOs of the same chemical class would have positive effect on QT prolongation. To further confirm these findings and draw a definitive conclusion, a retrospective analysis was performed to evaluate the effects of $2^{\prime}$-MOE ASO treatment on cardiac safety, based on ER analyses of ten $2^{\prime}$-MOE ASOs that had completed Phase 1 clinical studies in healthy subjects conducted by Ionis Pharmaceuticals, Inc. between 2003 and 2014 , and results of this analysis are summarized in this article.

\section{Materials and Methods}

\section{Oligonucleotides}

The 10 ASOs included in this retrospective PK-QT analysis are phosphorothioate oligonucleotides with 17 or 20 nucleotides in length, and 2'-MOE sugar modifications on both the $3^{\prime}$ - and $5^{\prime}$-ends of the molecules (underlined) (Table 1). In addition, all the cytosines of the compound were modified to contain a 5-methyl group (5-methylcytosine). These ASOs were formulated in sterile water for injection $(200 \mathrm{mg} / \mathrm{mL})$ and were provided by Ionis Pharmaceuticals, Inc. The molecular targets for these ASOs are listed in Table 1, all reside in the liver.

\section{Statement of regulatory approval for the human work performed}

All studies were performed according to the amended Declaration of Helsinki, and all patients provided written informed consent.

TABle 1 . List of $2^{\prime}$-O-Methoxyethyl-Modified Antisense OligonuCleotides InCLUded IN The Pharmacokinetics-QT ANALYSIS

\begin{tabular}{llcccc}
\hline Compound number & Target & Chemistry motif & Length & Molecular weight & Sequence \\
\hline ISIS 301012 & Apo B & $5-10-5$ & 20 & 7,177 & GCCTCAGTCTGCTTCGCACC \\
ISIS 304801 & apoC-III & $5-10-5$ & 20 & 7,165 & AGCTTCTTGTCCAGCTTTAT \\
ISIS 505358 & HBV & $5-10-5$ & 20 & 7,344 & GCAGAGGTGAAGCGAAGTGC \\
ISIS 463588 & FGFR4 & $5-10-5$ & 20 & 7,203 & GCACACTCAGCAGGACCCCC \\
ISIS 416858 & FXI & $5-10-5$ & 20 & 7,250 & ACGGCATTGGTGCACAGTTT \\
ISIS 420915 & TTR & $5-10-5$ & 20 & 7,183 & TCTTGGTTACATGAA $\overline{\text { ATCCC }}$ \\
ISIS 404173 & PTP1B & $5-10-5$ & 20 & 7,209 & AATGGTTTATTCCATGGCCA \\
ISIS 329993 & CRP & $5-10-5$ & 20 & 7,216 & AGCATAGTTAACGAGCTCCC \\
ISIS 546254 & PKK & $5-10-5$ & 20 & 7,217 & TGCAAGTCTCTTGGCAAACA \\
ISIS 449884 & GCGR & $3-10-4$ & 17 & 6,047 & $\underline{\text { GGTTCCCGAGGTGCCCA }}$ \\
\hline
\end{tabular}

Underlines denoted 2'-MOE sugar modifications on both the $3^{\prime}$ - and $5^{\prime}$-ends of the molecules.

MW, molecular weight. 
Table 2. Summary of Clinical Studies Included in the Pharmacokinetics-QT Analysis

\begin{tabular}{|c|c|c|c|c|}
\hline Compound & Study number & Dose levels tested (mg) & $\begin{array}{c}\text { Route of } \\
\text { administration }\end{array}$ & $\begin{array}{l}\text { Number of subjects } \\
\text { total (active:placebo) }\end{array}$ \\
\hline ISIS 301012 & ISIS 301012-CS1 & $50,100,200$, and 400 & 2-h IV and SC & $36(29: 7)$ \\
\hline ISIS 304801 & ISIS 304801-CS1 & $50,100,200$, and 400 & $\mathrm{SC}$ & $33(25: 8)$ \\
\hline ISIS 505358 & ISIS 505358-CS1 & $75,150,300$, and 450 & $\mathrm{SC}$ & $28(21: 7)$ \\
\hline ISIS 463588 & ISIS 463588-CS1 & $50,100,200$, and 400 & $\mathrm{SC}$ & $48(36: 12)$ \\
\hline ISIS 416858 & ISIS 416858-CS1 & $50,100,200$, and 300 & $\mathrm{SC}$ & $88(66: 22)$ \\
\hline ISIS 420915 & ISIS 420915-CS1 & $50,100,200,300$, and 400 & $\mathrm{SC}$ & $65(51: 14)$ \\
\hline ISIS 404173 & ISIS 404173-CS1 & $50,100,200$, and 400 & $\mathrm{SC}$ & $48(36: 12)$ \\
\hline ISIS 329993 & ISIS 329993-CS1 & $50,100,200,400$, and 600 & 2-h IV and SC & $80(60: 20)$ \\
\hline ISIS 546254 & ISIS 546254-CS1 & $50,100,200$, and 400 & $\mathrm{SC}$ & $49(37: 12)$ \\
\hline ISIS 449884 & ISIS 449884-CS1 & $50,100,200$, and 400 & SC & $52(39: 13)$ \\
\hline
\end{tabular}

IV, intravenous; SC, subcutaneous.

\section{Phase 1 dose-escalation clinical studies}

The Phase 1 studies conducted for the 10 aforementioned 2'-MOE ASOs were double-blind, placebo-controlled, doseescalation studies, designed to assess the safety, tolerability, PK, and pharmacodynamics of single dose (SD) and multiple doses (MDs) of the ASOs in healthy subjects.

The dose levels in these studies ranged from 50 to $450 \mathrm{mg}$ administered via SC injection (two studies also included 2-h IV infusion up to $600 \mathrm{mg}$ ), evaluated sequentially with $3: 1$ or 4:1 randomization to active ASO treatment or placebo, in the SD and MD cohorts (Table 2). Subjects enrolled in the MD cohorts typically received a loading dose on alternate days during the first week (Days 1, 3, and 5) and then once a week for the next 3-5 weeks. Two of the ten studies (ISIS 301012-CS1 and ISIS 329993-CS1) also included 2-h IV infusion cohorts, in addition to the SC administration cohorts. A total of 527 subjects enrolled in these 10 Phase 1 studies; 400 of the 527 subjects received active ASO treatment, while 127 subjects received placebo (Table 2). Baseline demographics for all included clinical studies are summarized in Table 3.

Intensive PK blood sampling occurred for $24 \mathrm{~h}$ following the dose in SD cohorts, and following both the first and last dose of the MD cohorts. In addition, post-treatment samples at various times up to 14 days in the SD cohorts, through (predose) plasma samples during treatment period, and posttreatment samples up to 70 days after the last SC dose in the MD cohorts were also collected.

In these Phase 1 studies, electrocardiograms (ECGs) were performed using calibrated 12-lead ECG machines. Twelvelead ECGs (single measurement at each time point) were typically collected during screening, before dosing on Day 1 (baseline), 1-7 h postdose on Day 1 (at or near $C_{\max }$ ), and 12 or $24 \mathrm{~h}$ postdose in all subjects, including placebo in the SD and MD cohorts, and on various days during treatment period (predose) and post-treatment follow-up period in the MD cohorts. In addition, 12-lead ECGs at time points listed above were also performed following the last dose administration in the MD treatment cohorts in some studies. The following cardiac variables were assessed from continuous 12-lead ECG: VR, and RR, PR, QRS, and QT intervals. QT corrected using Bazett's formula (QTcB) and corrected using Fridericia's formula $(\mathrm{QTcF})$ was calculated by $\mathrm{QTcB}=\mathrm{QT} /(\mathrm{RR})^{1 / 2}$ and $\mathrm{QTcF}=\mathrm{QT} /(\mathrm{RR})^{1 / 3}$, respectively, where $R R=60 / V R$.

\section{Bioanalytical sample analyses}

Human plasma samples for quantitation of oligonucleotide concentrations were analyzed using a quantitative, sensitive, and selective hybridization enzyme-linked immunosorbent assay method, which is a variation of the method reported previously [18]. The plasma assay was validated for precision, accuracy, selectivity, sensitivity, and stability of mipomersen in human plasma. Plasma sample analyses were performed in compliance with the Principles of Good Laboratory Practice [19]. The assay was tested with synthesized putative short oligonucleotide metabolite standards and showed no measurable cross-reactivity confirming the assay specificity for the parent oligonucleotide. Although this methodology can cross-react, to some degree, with long-chain oligonucleotide metabolites (eg, 19-mer), the presence of 19-mer metabolite of oligonucleotides of the same chemical class as mipomersen in plasma is very minor [20], and thus, the assay can be considered specific for the parent compound for this chemical class. The lower limit of quantitation was determined to be in the range of $1.00-2.00 \mathrm{ng} / \mathrm{mL}$ for the assays used to support the Phase 1 dose-escalation studies.

\section{ER statistical analysis}

Descriptive statistics for PK plasma concentrations and corresponding QT levels were calculated using WinNonLin Professional Version 5.0 or higher, SAS Version 9, or Microsoft Excel. BLQ values (below the limit of quantitation) were treated as " 0 " in the calculation of descriptive statistics.

In the Phase 1 dose-escalation studies, an ER analysis was used to explore the relationship between plasma drug concentrations and time-matched QTcF. Before ER analysis, the lack of hysteresis was confirmed. The primary variables were change from baseline in QTcF without and with adjustment for placebo for each study $(\Delta \mathrm{QTcF}$ and $\Delta \Delta \mathrm{QTcF})$. Since there was no placebo treatment within subjects receiving active ASO treatment in the Phase 1 dose-escalation studies, mean $\Delta \mathrm{QTcF}$ by time point was calculated for pooled placebo subjects. Subsequently, $\Delta \Delta \mathrm{QTCF}$ was calculated by $\Delta \mathrm{QTcFDT}[\mathrm{i}]-\Delta \mathrm{QTcFP}[\mathrm{i}]$, where $\Delta \mathrm{QTcFDT}[\mathrm{i}]$ was defined as the change from baseline at time point $i$ for QTcF in subjects who received active ASO treatment, and $\Delta \mathrm{QTcFP}[\mathrm{i}]$ was the mean change from baseline at time point $\mathrm{i}$ for QTcF in the pooled placebo subjects (per Phase 1 dose-escalation study).

A linear mixed-effects approach was performed (using lme package in $\mathrm{R}$ version 3.2.1) for the change from baseline in 
Table 3. Summary of Demographics and Baseline Characteristics FOR THE Clinical Studies Included IN THE PK-QT ANAlysis

\begin{tabular}{|c|c|c|c|c|c|c|c|c|c|}
\hline \multirow{2}{*}{$\frac{\text { Study number }}{\text { ISIS 301012-CS1 }}$} & \multirow{2}{*}{$\begin{array}{l}\mathrm{N} \\
36\end{array}$} & \multicolumn{2}{|c|}{ Gender, n (\%) } & \multicolumn{2}{|c|}{ Race, n (\%) } & \multicolumn{2}{|c|}{ Age (years) } & \multicolumn{2}{|c|}{ Weight $(\mathrm{kg})$} \\
\hline & & $\begin{array}{l}\text { Female } \\
\text { Male }\end{array}$ & $\begin{array}{l}18(50.0) \\
18(50.0)\end{array}$ & White & $36(100.0)$ & $\begin{array}{l}\text { Mean (SD) } \\
\text { Median } \\
\text { Min-Max }\end{array}$ & $\begin{array}{c}52(9) \\
54 \\
30-64\end{array}$ & $\begin{array}{l}\text { Mean (SD) } \\
\text { Median } \\
\text { Min-Max }\end{array}$ & $\begin{array}{c}74.9(11.1) \\
77.2 \\
53.1-95.3\end{array}$ \\
\hline ISIS 304801-CS1 & 33 & $\begin{array}{l}\text { Female } \\
\text { Male }\end{array}$ & $\begin{array}{c}2(6.1) \\
31(93.9)\end{array}$ & $\begin{array}{l}\text { Asian } \\
\text { Black } \\
\text { White }\end{array}$ & $\begin{array}{r}4(12.1) \\
7(21.2) \\
22(66.7)\end{array}$ & $\begin{array}{l}\text { Mean (SD) } \\
\text { Median } \\
\text { Min-Max }\end{array}$ & $\begin{array}{c}43(7) \\
43 \\
28-54\end{array}$ & $\begin{array}{l}\text { Mean (SD) } \\
\text { Median } \\
\text { Min-Max }\end{array}$ & $\begin{array}{c}78.6(12.1) \\
76.5 \\
56.4-110.4\end{array}$ \\
\hline ISIS 329993-CS1 & 80 & $\begin{array}{l}\text { Female } \\
\text { Male }\end{array}$ & $\begin{array}{l}10(12.5) \\
70(87.5)\end{array}$ & $\begin{array}{l}\text { Asian } \\
\text { Black } \\
\text { White }\end{array}$ & $\begin{array}{c}1(1.3) \\
2(2.5) \\
77(96.3)\end{array}$ & $\begin{array}{l}\text { Mean (SD) } \\
\text { Median } \\
\text { Min-Max }\end{array}$ & $\begin{array}{c}37(11) \\
39 \\
18-55\end{array}$ & $\begin{array}{l}\text { Mean (SD) } \\
\text { Median } \\
\text { Min-Max }\end{array}$ & $\begin{array}{c}76.6(10.8) \\
78.0 \\
47.1-116.5\end{array}$ \\
\hline ISIS 404173-CS1 & 48 & $\begin{array}{l}\text { Female } \\
\text { Male }\end{array}$ & $\begin{array}{l}12(25.0) \\
36(75.0)\end{array}$ & $\begin{array}{l}\text { Asian } \\
\text { Black } \\
\text { White } \\
\text { Other }\end{array}$ & $\begin{aligned} 4 & (8.3) \\
5 & (10.4) \\
38 & (79.2) \\
1 & (2.1)\end{aligned}$ & $\begin{array}{l}\text { Mean (SD) } \\
\text { Median } \\
\text { Min-Max }\end{array}$ & $\begin{array}{c}49(11) \\
52 \\
21-62\end{array}$ & $\begin{array}{l}\text { Mean (SD) } \\
\text { Median } \\
\text { Min-Max }\end{array}$ & $\begin{array}{c}85.3(12.2) \\
84.6 \\
60.0-113.0\end{array}$ \\
\hline ISIS 416858-CS1 & 88 & $\begin{array}{l}\text { Female } \\
\text { Male }\end{array}$ & $\begin{array}{l}25 \text { (28.4) } \\
63(71.6)\end{array}$ & $\begin{array}{l}\text { Asian } \\
\text { Black } \\
\text { White }\end{array}$ & $\begin{array}{c}7(8.0) \\
16(18.2) \\
65(73.9)\end{array}$ & $\begin{array}{l}\text { Mean (SD) } \\
\text { Median } \\
\text { Min-Max }\end{array}$ & $\begin{array}{c}45(12) \\
48 \\
19-64\end{array}$ & $\begin{array}{l}\text { Mean (SD) } \\
\text { Median } \\
\text { Min-Max }\end{array}$ & $\begin{array}{c}72.6(10.5) \\
73.3 \\
53.1-95.7\end{array}$ \\
\hline ISIS 420915-CS1 & 65 & $\begin{array}{l}\text { Female } \\
\text { Male }\end{array}$ & $\begin{array}{l}19(29.2) \\
46(70.8)\end{array}$ & $\begin{array}{l}\text { Asian } \\
\text { Black } \\
\text { White }\end{array}$ & $\begin{array}{c}5(7.7) \\
17(26.2) \\
43(66.2)\end{array}$ & $\begin{array}{l}\text { Mean (SD) } \\
\text { Median } \\
\text { Min-Max }\end{array}$ & $\begin{array}{l}43(9) \\
43 \\
25-55\end{array}$ & $\begin{array}{l}\text { Mean (SD) } \\
\text { Median } \\
\text { Min-Max }\end{array}$ & $\begin{array}{c}76.3(11.2) \\
77.1 \\
50.2-104.4\end{array}$ \\
\hline ISIS 449884-CS1 & 51 & $\begin{array}{l}\text { Female } \\
\text { Male }\end{array}$ & $\begin{array}{l}17(33.3) \\
34(66.7)\end{array}$ & $\begin{array}{l}\text { Asian } \\
\text { Black } \\
\text { White } \\
\text { Other }\end{array}$ & $\begin{aligned} 2 & (3.9) \\
1 & (2.0) \\
47 & (92.2) \\
1 & (2.0)\end{aligned}$ & $\begin{array}{l}\text { Mean (SD) } \\
\text { Median } \\
\text { Min-Max }\end{array}$ & $\begin{array}{c}50(11) \\
53 \\
22-65\end{array}$ & $\begin{array}{l}\text { Mean (SD) } \\
\text { Median } \\
\text { Min-Max }\end{array}$ & $\begin{array}{c}82.2(11.1) \\
83.4 \\
56.0-109.8\end{array}$ \\
\hline ISIS 463588-CS1 & 48 & $\begin{array}{l}\text { Female } \\
\text { Male }\end{array}$ & $\begin{array}{l}16(33.3) \\
32(66.7)\end{array}$ & $\begin{array}{l}\text { Asian } \\
\text { Black } \\
\text { White }\end{array}$ & $\begin{array}{c}1(2.1) \\
9(18.8) \\
38(79.2)\end{array}$ & $\begin{array}{l}\text { Mean (SD) } \\
\text { Median } \\
\text { Min-Max }\end{array}$ & $\begin{array}{c}47(10) \\
50 \\
21-62\end{array}$ & $\begin{array}{l}\text { Mean (SD) } \\
\text { Median } \\
\text { Min-Max }\end{array}$ & $\begin{array}{c}86.0(11.2) \\
86.8 \\
65.4-118.5\end{array}$ \\
\hline ISIS 505358-CS1 & 28 & $\begin{array}{l}\text { Female } \\
\text { Male }\end{array}$ & $\begin{array}{r}6(21.4) \\
22(78.6)\end{array}$ & $\begin{array}{l}\text { Black } \\
\text { White }\end{array}$ & $\begin{array}{r}4(14.3) \\
24(85.7)\end{array}$ & $\begin{array}{l}\text { Mean (SD) } \\
\text { Median } \\
\text { Min-Max }\end{array}$ & $\begin{array}{c}49(11) \\
53 \\
27-62\end{array}$ & $\begin{array}{l}\text { Mean (SD) } \\
\text { Median } \\
\text { Min-Max }\end{array}$ & $\begin{array}{c}80.1(10.7) \\
83.0 \\
59.4-99.8\end{array}$ \\
\hline ISIS 546254-CS1 & 49 & $\begin{array}{l}\text { Female } \\
\text { Male }\end{array}$ & $\begin{array}{l}19(38.8) \\
30(61.2)\end{array}$ & $\begin{array}{l}\text { Asian } \\
\text { Black } \\
\text { White } \\
\text { Other }\end{array}$ & $\begin{aligned} 7 & (14.3) \\
8 & (16.3) \\
33 & (67.3) \\
1 & (2.0)\end{aligned}$ & $\begin{array}{l}\text { Mean (SD) } \\
\text { Median } \\
\text { Min-Max }\end{array}$ & $\begin{array}{c}53(9) \\
56 \\
19-65\end{array}$ & $\begin{array}{l}\text { Mean (SD) } \\
\text { Median } \\
\text { Min-Max }\end{array}$ & $\begin{array}{c}73.6(13.5) \\
73.1 \\
45.6-103.4\end{array}$ \\
\hline
\end{tabular}

Baseline is defined as the last non-missing value prior to the first dose of study drug.

QTcF intervals without and with placebo adjustment $(\Delta \mathrm{QTcF}$ and $\Delta \Delta \mathrm{QTcF}$ ) versus drug plasma concentrations, with intercept, plasma concentration, and subject included as a random effect [see Eq. (1)].

$$
\begin{aligned}
\Delta \mathrm{QTcF} \text { or } \Delta \Delta \mathrm{QTcF}= & \alpha+\beta \times(\text { plasma concentration }) \\
& +\gamma \times(\text { subject effect })
\end{aligned}
$$

This model was used to estimate both the fixed effect and the random effect of the intercept and the slope, respectively. The predicted maximum effect, as well as the upper bound of the two-sided $90 \%$ confidence interval (CI), was calculated using the following two equations:

Mean maximum effect: $\alpha+C_{\max } \times \beta$ or $\alpha+2 \times C_{\max } \times \beta$

Upper two-sided $90 \% \mathrm{CI}: \quad \alpha+C_{\max } \times\left(\beta+1.645 \times \mathrm{SE}_{\beta}\right)$ or $\alpha+2 \times C_{\max } \times\left(\beta+1.645 \times \mathrm{SE}_{\beta}\right)$ where $C_{\max }$ was the geometric mean $C_{\max }$ following the last dose in the MD cohort of their respective therapeutic dose level for all studies with the exception of ISIS 301012-CS1, ISIS 304801-CS1, and ISIS 463588-CS1. For Study ISIS 301012, the reported $C_{\max }$ was pooled from multiple clinical studies, including patient population was used because of its availability and large sample size [21]. For ISIS 304801-CS1 and ISIS 463588-CS1, the $C_{\max }$ was interpolated from linear regression of dose $\sim C_{\max }$ based on log-transformed data [ie, $\log ($ dose $\left.) \sim \log \left(C_{\max }\right)\right]$ because the clinical therapeutic dose $(300 \mathrm{mg}$ ) was not conducted in the Phase 1 study.

The highest clinically relevant plasma exposures for 2 'MOE ASOs are mostly below two-times $C_{\max }$ at the clinical dose levels (typically 200 or $300 \mathrm{mg}$ ), since (i) ASOs normally have a low to moderate intersubject variability in PK exposure following either SC or IV administration (\% coefficient of variation [CV] typically ranged 25\%-50\%); (ii) there is no to minimal accumulation in $C_{\max }$ following multiple dose, and (iii) there were no drug-drug interactions observed thus far in clinic nor expected with this class of compounds [9-11]. Thus, to estimate the risk and maximum $\Delta \Delta \mathrm{QTcF}$ change for a given drug, a $2 \times$ geometric mean $C_{\max }$ 


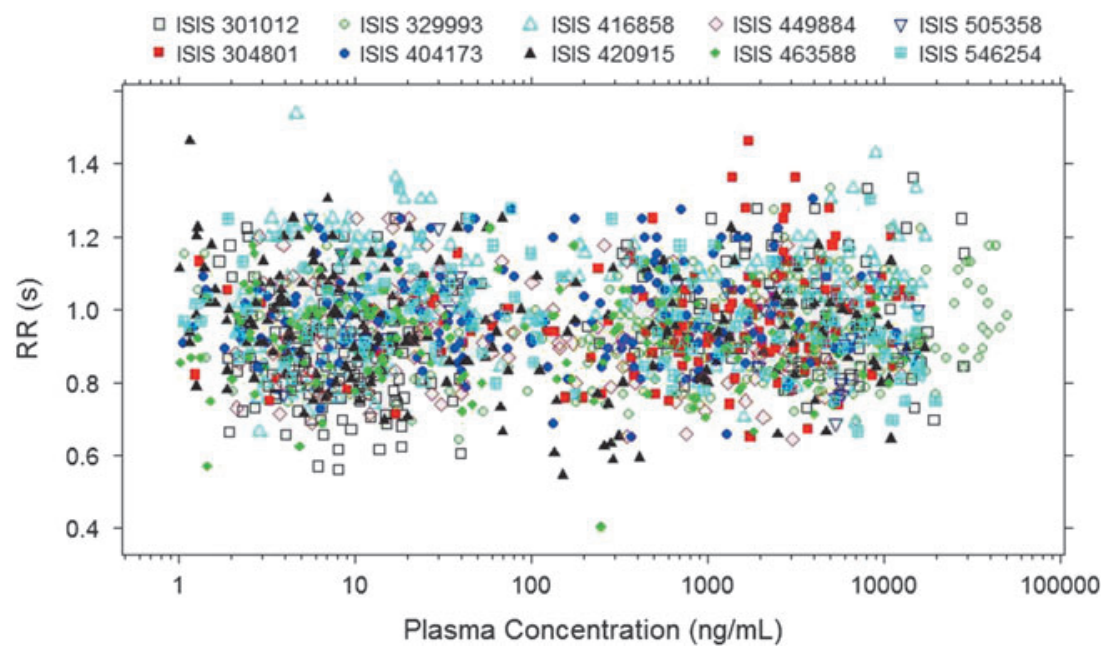

FIG. 1. RR as a function of ASO plasma concentrations for the 10 Phase 1 studies pooled. ASO, antisense oligonucleotide. value is used based on the linear mixed-effects model established as described above.

The criteria used for a negative QT assessment was based on the ICH E14 guidance on alternative approach to the TQT study [17]. Therefore, the absence of a concentrationdependent effect on $\Delta \Delta \mathrm{QTcF}$ with $2^{\prime}$-MOE ASO treatment was concluded if as follows.

The upper bound of the two-sided $90 \% \mathrm{CI}$ of the predicted $\Delta \Delta \mathrm{QTcF}$ at highest clinical concentration (ie, $2 \times C_{\max }$ of the clinical therapeutic dose) was $<10 \mathrm{~ms}$.

\section{Results}

\section{Graphical analysis}

The relationship between plasma ASO concentrations with $\mathrm{RR}, \mathrm{QTcF}$, and $\Delta \Delta \mathrm{QTcF}$ was examined graphically for the data pooled from all 10 Phase 1 studies for the ten $2^{\prime}$-MOE ASOs evaluated. Plasma concentrations were plotted on logarithmic scale due to the large range of concentrations observed in the clinic ( $>4-\log$ of magnitude). Indeed, the highest concentration observed $(>50,000 \mathrm{ng} / \mathrm{mL})$ was 4-20 times the $C_{\text {max }}$ of therapeutic dose for the ten $2^{\prime}$-MOE ASOs evaluated because two of the ten studies included had IV infusion cohorts in addition to SC administration cohorts (Figs. 1-3).
As shown in Figs. 1-3, a flat relationship was obtained between plasma ASO concentrations and RR, QTcF, and $\Delta \Delta \mathrm{QTcF}$, respectively, demonstrating ASO treatment had no effect on QT intervals for all ten 2'-MOE ASOs evaluated. Inspection of the QTcF versus concentration data suggested a linear model would be adequate to describe the relationship.

Since only a single ECG measurement was made at each time point in these Phase 1 studies, the ECG measurements were prone to have outliers. Therefore, all the ECG data were carefully evaluated graphically and examined for outliers.

As shown in Figs. 1 and 2, there were only two ECG measurements (QTcF $>500 \mathrm{~ms}, \Delta \Delta \mathrm{QTcF}>100 \mathrm{~ms}$ ) identified as outliers from these 10 studies (one outlier at $72 \mathrm{~h}$ in ISIS $404173 \mathrm{CS} 1$ and one outlier at $3 \mathrm{~h}$ in ISIS 449884-CS1). These two observations were concluded as outliers because (i) the $\Delta \Delta \mathrm{QTcF}$ values before and after the outlier were normal and (ii) the time-matched plasma concentrations associated with the outliers were not at $C_{\max }$. These two outliers were excluded from ER analysis. Since only two outliers (of a total of 2,703 observations) were identified among the 10 Phase 1 studies, the quality of the overall ECG data was considered to be reliable.

In addition, the relationship between plasma ASO concentrations with $\Delta \Delta \mathrm{QTcF}$ was examined graphically for each individual study. A flat relationship was obtained for all the

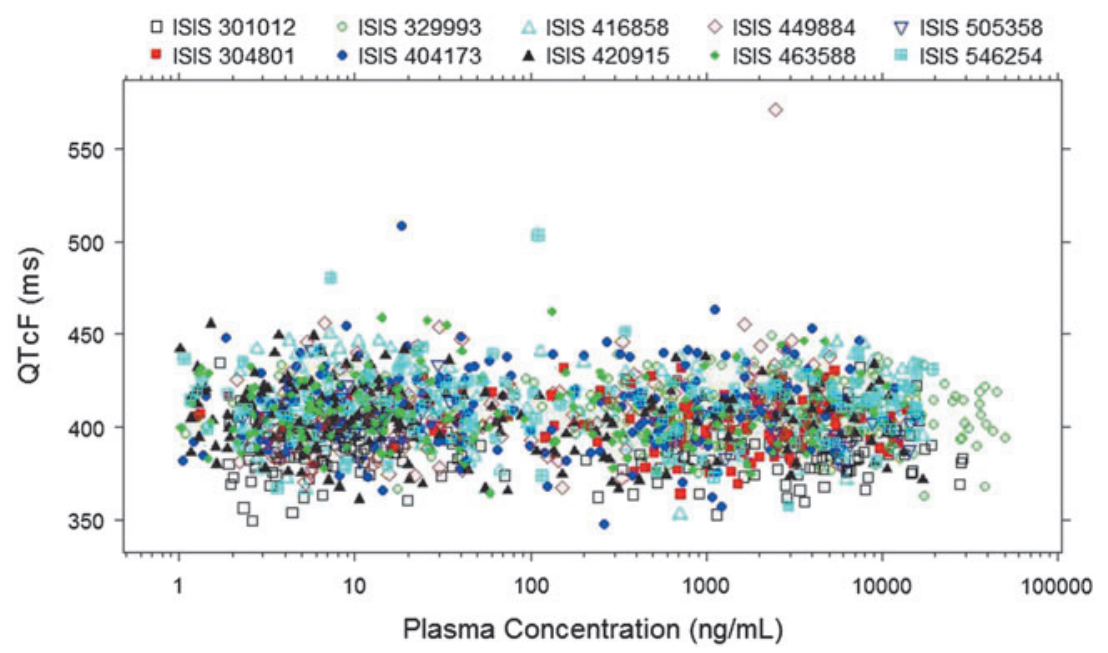

FIG. 2. QTcF as a function of $\mathrm{ASO}$ plasma concentrations for the 10 Phase 1 studies pooled. 
FIG. 3. $\Delta \Delta \mathrm{QTcF}$ as a function of $\mathrm{ASO}$ plasma concentrations for the 10 Phase 1 studies pooled.

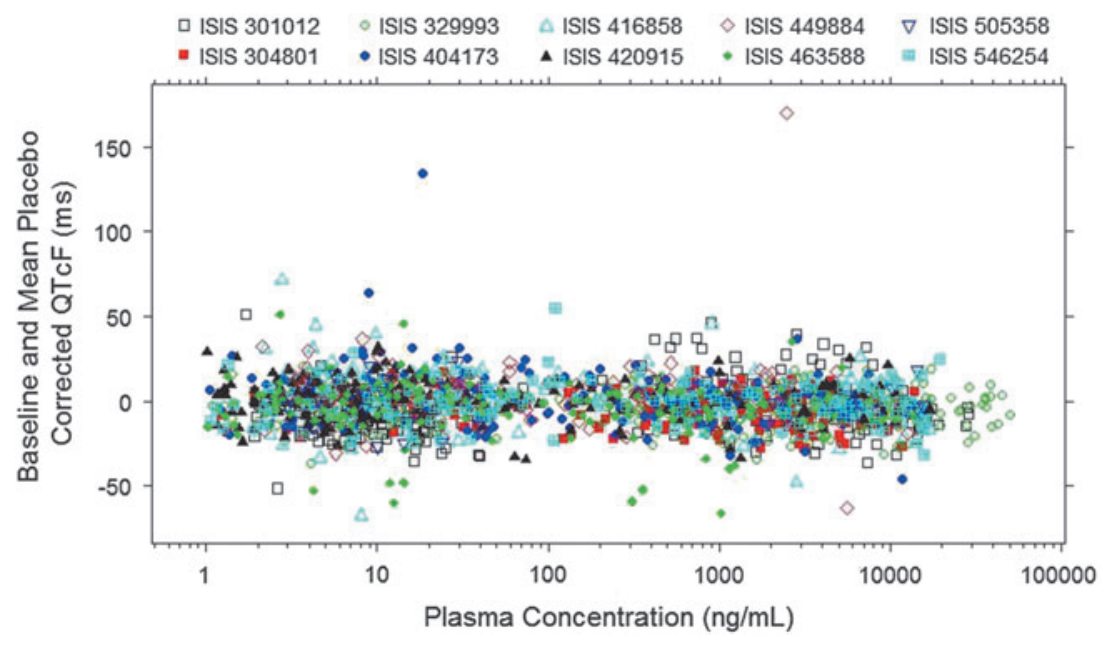

ten 2 '-MOE ASOs evaluated individually between plasma ASO concentrations and $\Delta \Delta \mathrm{QTcF}$, further demonstrating that ASO treatment had no effect on QT intervals.

\section{Central tendency analysis}

Following SC administrations of $2^{\prime}$-MOE ASOs, the maximum plasma concentrations $\left(C_{\max }\right)$ were typically observed within only a few hours after SC dosing.

Box plots of the $\Delta \Delta \mathrm{QTCF}$ at the $C_{\max }$ of the time-matched PK-ECG data set for all ASO treatment doses pooled by study and at each dose level within each Phase 1 study are presented in Figs. 4 and 5, respectively.

The median $\Delta \Delta \mathrm{QTcF}$ at the $C_{\max }$ for all 10 Phase 1 studies was around zero (Fig. 4). In addition, median $\Delta \Delta \mathrm{QTcF}$ at $C_{\max }$ appeared to be independent of dose, further confirming the lack of ASO treatment effect on QT intervals (Fig. 5).

It was noted that the median $\Delta \Delta \mathrm{QTcF}$ following $\mathrm{SC}$ injection of ISIS 301012 (mipomersen) was $>10 \mathrm{~ms}$ at all dose levels evaluated (50-400 mg) but was dose independent. Meanwhile, median $\Delta \Delta \mathrm{QTcF}$ following 2-h infusion of ISIS 301012 (with plasma concentrations much higher than those following $\mathrm{SC}$ injection) was around $0 \mathrm{~ms}$ (much $<10 \mathrm{~ms}$ ), suggesting that the increase in QTcF observed following SC injection may not have been related to ISIS 301012 treatment. Moreover, the lack of QT effect with ISIS 301012 treatment was further confirmed by ER analysis in this study (Section 1.7) and in the subsequent TQT study. ${ }^{10}$

\section{ER analysis}

A linear mixed-effects modeling approach was used to characterize the relationship for each individual 2'-MOE ASO between the change from baseline in QTcF intervals with placebo adjustment $(\Delta \Delta \mathrm{QTcF})$ and drug plasma concentrations, with subject included as a random effect. Two ECG measurements (QTcF >500 ms, $\Delta \Delta \mathrm{QTcF}>100 \mathrm{~ms}$ ) were identified as outliers (one outlier in ISIS 404173-CS1

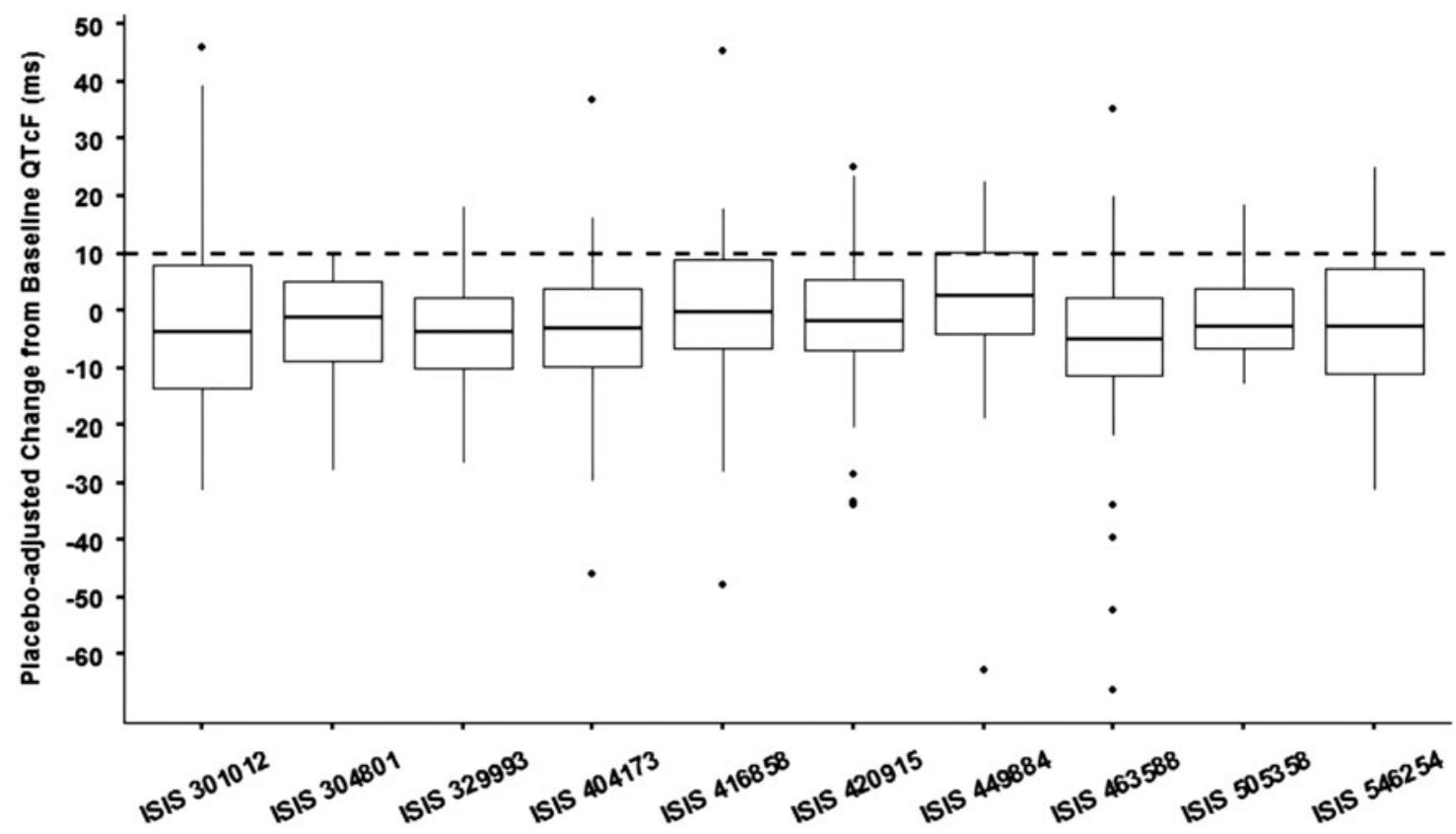

FIG. 4. $\Delta \Delta \mathrm{QTcF}$ at the maximum concentration $\left(C_{\max }\right)$ for the 10 Phase 1 studies. 


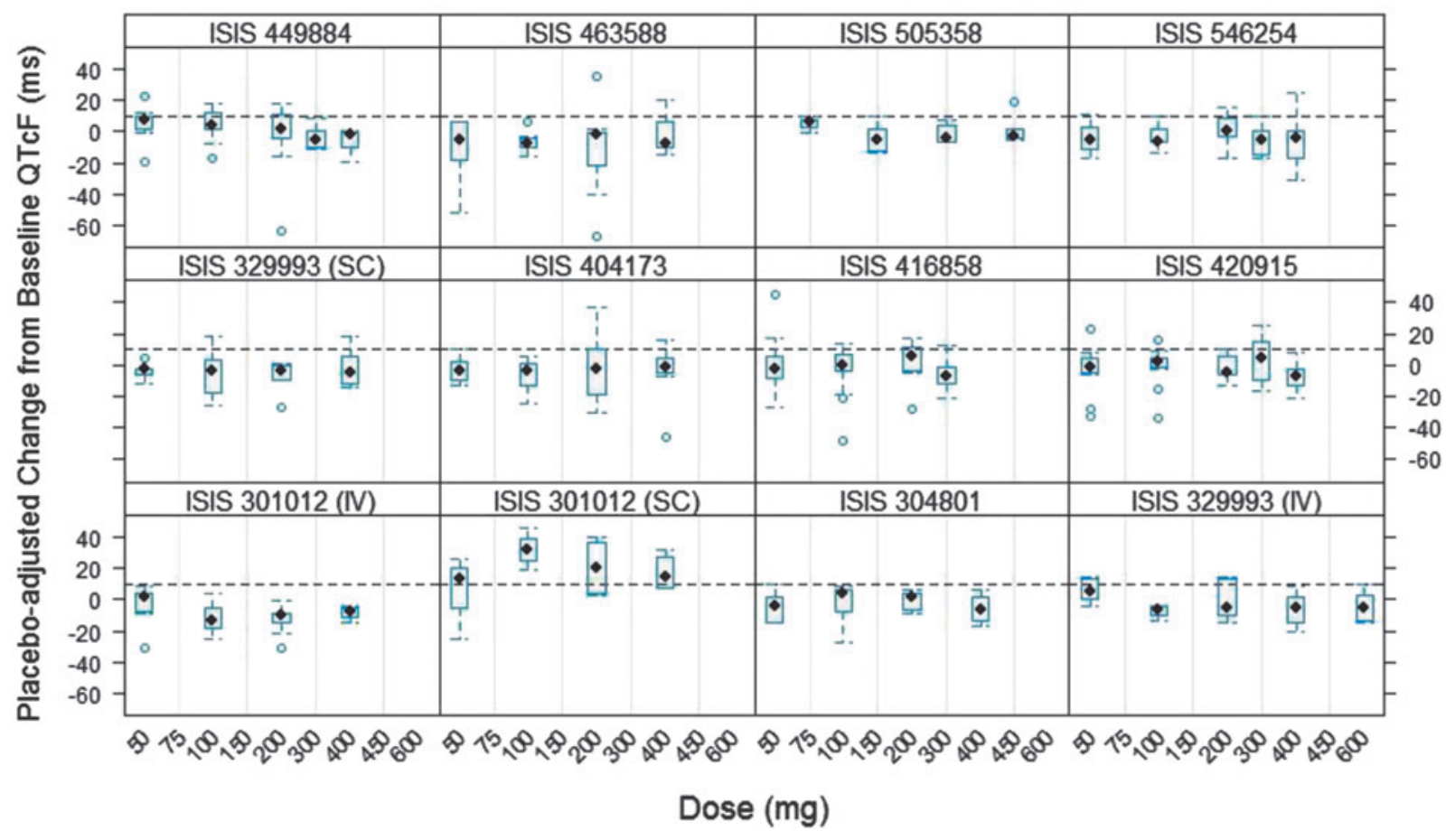

FIG. 5. Placebo-adjusted change from baseline QTcF as a function of dose from 10 Phase 1 studies.

and one outlier in ISIS 449884-CS1) and were excluded from the ER analysis as explained previously.

The parameter estimates of the ER analysis for the ten $2^{\prime}$ MOE ASOs in Phase 1 studies are summarized in Table 4. All of the slopes of the ER analysis were approximately zero, suggesting that there was no concentration-dependent increase in $\Delta \Delta \mathrm{QTcF}$ following ASO treatment. In addition, the upper two-sided $90 \% \mathrm{CI}$ at both the $C_{\max }$ and $2 \times C_{\max }$ of the clinical therapeutic dose (the highest clinical concentrations) for all the ten $2^{\prime}$-MOE ASOs was below $10 \mathrm{~ms}$ threshold (Tables 5 and $6)$; therefore, the absence of a concentration-dependent effect of 2'-MOE ASO on QT prolongation was concluded.

\section{Discussion}

This retrospective analysis of the effects of $2^{\prime}$-MOE ASO treatment on cardiac safety was based on exposure (PK)/ response (QTcF) analyses of ten $2^{\prime}$-MOE ASOs that had completed Phase 1 clinical studies in healthy subjects, conducted by Ionis Pharmaceuticals, Inc. between 2003 and 2014. These studies included a wide dose range (50-450 mg for SC and up to $600 \mathrm{mg}$ for IV) and the ECG measurement included the collection time at or near $C_{\max }$. Two of the ten studies (ISIS 301012-CS1 and ISIS 329993-CS1) also included 2-h IV infusion cohorts, in addition to the SC administration cohorts. The combined data from 10 Phase 1 studies where time-matched PK-QT samples collected were over a wide dose and concentration range provided valuable information and robust analysis of ER relationships for $2^{\prime}-\mathrm{MOE}$ ASOs. The maximum dose evaluated in these Phase 1 studies was $450 \mathrm{mg}$ (for SC and $600 \mathrm{mg}$ for IV), exceeded the clinical dose of 200 or $300 \mathrm{mg}$ (SC) used in subsequent studies in patents, and the highest observed plasma concentration was 4 20 times the $C_{\max }$ of therapeutic dose. Therefore, the exposures achieved in these studies should be able to cover exposures at different clinical scenarios because of (i) the modest intersubject variability following SC administration, (ii) the lack of accumulation in $C_{\max }$ on repeated dosing, and (iii) the lack of drug-drug interactions at both the CYP enzyme level and transporter level with this class of compounds [9-11].

Overall, there was neither treatment nor dose-dependent effect on the QTcF and RR for all the ten 2'-MOE ASOs evaluated. There was no evidence for QTc prolongation associated with increasing plasma ASO concentrations in healthy subjects, including supratherapeutic exposures up to $450 \mathrm{mg}$ administered SC or $600 \mathrm{mg}$ by IV infusions, and ASO concentrations that are 4-20 times the $C_{\max }$ of therapeutic dose, as assessed by both QTcF and change from baseline in QTcF with placebo adjustment $(\Delta \Delta \mathrm{QTCF})$. Moreover, the ER analysis of the relationship between drug plasma concentration and $\Delta \Delta \mathrm{QTcF}$ for each compound was further investigated using a linear mixed-effects approach. The results showed that the slope of the regression line was approximately zero for all ten 2 -MOE ASOs evaluated, indicating there was no concentration-dependent increase in $\Delta \Delta \mathrm{QTcF}$ following ASO treatment. In addition, the upper bound of the two-sided $90 \% \mathrm{CI}$ at the highest clinical concentration ( $2 \times C_{\max }$ of the clinical therapeutic dose) was well below the $10 \mathrm{~ms}$ threshold for all the ten $2^{\prime}$-MOE ASOs (ICH 2015). Therefore, it was concluded that there is no concentrationdependent effect on QT prolongation for all ten $2^{\prime}$-MOE ASOs evaluated. These results further confirm that $2^{\prime}-\mathrm{MOE}$ ASOs, as a chemical class, do not cause QT prolongation.

The lack of QT effect by ASOs was further supported by a TQT study conducted for one of the ten 2'-MOE ASOs evaluated, that is, ISIS 301012 (mipomersen). This study was a randomized, double-blind, four-way crossover study to define the ECG effects of mipomersen using a therapeutic dose $(200 \mathrm{mg}$ 
Table 4. Parameter Estimates from Linear Mixed-Effects Model of $\Delta \Delta \mathrm{QTcF}$ Versus Plasma Concentrations (Exposure/Response Analysis)

\begin{tabular}{|c|c|c|c|}
\hline \multirow[b]{2}{*}{ Compound } & \multirow[b]{2}{*}{ Parameter } & \multicolumn{2}{|c|}{$\Delta \Delta Q T c F$} \\
\hline & & Estimate & Standard error \\
\hline ISIS 301012 & $\begin{array}{l}\text { Intercept, } \alpha(\mathrm{ms}) \\
\text { Slope, } \beta(\mathrm{ms} / \mathrm{ng} / \mathrm{mL})\end{array}$ & $\begin{array}{l}-3.58 \\
-0.000196\end{array}$ & $\begin{array}{l}1.63 \\
0.000199\end{array}$ \\
\hline ISIS $304801^{a}$ & $\begin{array}{l}\text { Intercept, } \alpha(\mathrm{ms}) \\
\text { Slope, } \beta(\mathrm{ms} / \mathrm{ng} / \mathrm{mL})\end{array}$ & $\begin{array}{l}-4.80 \\
-0.000227\end{array}$ & $\begin{array}{l}1.56 \\
0.000432\end{array}$ \\
\hline ISIS 505358 & $\begin{array}{l}\text { Intercept, } \alpha(\mathrm{ms}) \\
\text { Slope, } \beta(\mathrm{ms} / \mathrm{ng} / \mathrm{mL})\end{array}$ & $\begin{array}{l}-0.593 \\
-0.00000520\end{array}$ & $\begin{array}{l}1.73 \\
0.000314\end{array}$ \\
\hline ISIS 463588 & $\begin{array}{l}\text { Intercept, } \alpha(\mathrm{ms}) \\
\text { Slope, } \beta(\mathrm{ms} / \mathrm{ng} / \mathrm{mL})\end{array}$ & $\begin{array}{l}-2.77 \\
-0.000572\end{array}$ & $\begin{array}{l}1.82 \\
0.000497\end{array}$ \\
\hline ISIS 416858 & $\begin{array}{l}\text { Intercept, } \alpha(\mathrm{ms}) \\
\text { Slope, } \beta(\mathrm{ms} / \mathrm{ng} / \mathrm{mL})\end{array}$ & $\begin{array}{l}2.51 \\
-0.000451\end{array}$ & $\begin{array}{l}1.21 \\
0.000215\end{array}$ \\
\hline ISIS 420915 & $\begin{array}{l}\text { Intercept, } \alpha(\mathrm{ms}) \\
\text { Slope, } \beta(\mathrm{ms} / \mathrm{ng} / \mathrm{mL})\end{array}$ & $\begin{array}{l}0.302 \\
-0.0000964\end{array}$ & $\begin{array}{l}0.932 \\
0.000284\end{array}$ \\
\hline ISIS $404173^{\mathrm{b}}$ & $\begin{array}{l}\text { Intercept, } \alpha(\mathrm{ms}) \\
\text { Slope, } \beta(\mathrm{ms} / \mathrm{ng} / \mathrm{mL})\end{array}$ & $\begin{array}{l}2.41 \\
-0.00192\end{array}$ & $\begin{array}{l}1.37 \\
0.000923\end{array}$ \\
\hline ISIS 329993 & $\begin{array}{l}\text { Intercept, } \alpha(\mathrm{ms}) \\
\text { Slope, } \beta(\mathrm{ms} / \mathrm{ng} / \mathrm{mL})\end{array}$ & $\begin{array}{l}-2.50 \\
-0.0000804\end{array}$ & $\begin{array}{l}0.956 \\
0.0000652\end{array}$ \\
\hline ISIS 546254 & $\begin{array}{l}\text { Intercept, } \alpha(\mathrm{ms}) \\
\text { Slope, } \beta(\mathrm{ms} / \mathrm{ng} / \mathrm{mL})\end{array}$ & $\begin{array}{l}0.0191 \\
-0.000335\end{array}$ & $\begin{array}{l}1.18 \\
0.000250\end{array}$ \\
\hline ISIS $449884^{c}$ & $\begin{array}{l}\text { Intercept, } \alpha(\mathrm{ms}) \\
\text { Slope, } \beta(\mathrm{ms} / \mathrm{ng} / \mathrm{mL})\end{array}$ & $\begin{array}{l}3.30 \\
-0.000706\end{array}$ & $\begin{array}{l}1.23 \\
0.000827\end{array}$ \\
\hline
\end{tabular}

${ }^{\mathrm{a}}$ ISIS 304801-CS1 CSR.

${ }^{\mathrm{b}}$ One QT value $>500 \mathrm{~ms}$ was excluded due to abnormality and was deemed not clinically significant (ISIS 404173-CS1 CSR).

${ }^{\circ}$ One QT value $>500 \mathrm{~ms}$ was excluded, but the explanation is still pending (ISIS 449884-CS1 CSR).

SC), supratherapeutic dose (200 mg IV), compared with placebo, and positive control (400 mg moxifloxacin IV) [14]. Fiftyeight subjects enrolled in the study. Mean peak plasma exposure measures of mipomersen $\left(C_{\max }\right)$ were 5,860 and $22,100 \mathrm{ng} / \mathrm{mL}$ in the $200 \mathrm{mg}$ SC and $200 \mathrm{mg}$ IV mipomersen treatment groups,

Table 5. Predicted $\Delta \Delta \mathrm{QTCF}$ at the $C_{\mathrm{Max}}$ OF THERAPEUtic Doses

\begin{tabular}{lcrll}
\hline & & \multicolumn{3}{c}{ Predicted $\Delta \Delta Q T c F(\mathrm{~ms})$} \\
\cline { 5 - 5 } Compound & $\begin{array}{c}\text { Therapeutic } \\
\text { dose }(\mathrm{mg})\end{array}$ & $\begin{array}{c}C_{\text {max }} \text { a } \\
(\mathrm{ng} / \mathrm{mL})\end{array}$ & Estimate & $\begin{array}{c}\text { Upper two- } \\
\text { sided } 90 \% \text { CI }\end{array}$ \\
\hline ISIS 301012 $^{\mathrm{b}}$ & 200 & 5,160 & -4.59 & -2.90 \\
ISIS 304801 $^{\mathrm{c}}$ & 300 & 6,876 & -6.36 & -1.47 \\
ISIS 505358 & 300 & 7,704 & -0.633 & 3.35 \\
ISIS 463588 & 300 & 5,152 & -5.72 & -1.50 \\
ISIS 416858 & 300 & 11,400 & -2.63 & 1.40 \\
ISIS 420915 & 300 & 7,090 & -0.38 & 2.93 \\
ISIS 404173 & 200 & 2,900 & -3.16 & 1.25 \\
ISIS 329993 & 200 & 4,976 & -2.90 & -2.37 \\
ISIS 546254 & 300 & 10,600 & -3.53 & 0.83 \\
ISIS 449884 & 100 & 1,620 & 2.16 & 4.36 \\
\hline
\end{tabular}

${ }^{\mathrm{a}} C_{\max }$ is the observed geometric mean $C_{\max }$ following the last dose in the MD cohort of therapeutic dose level for all studies except noted.

${ }^{\mathrm{b}} C_{\max }$ was obtained from Li et al. [21].

${ }^{\mathrm{c}} C_{\max }$ was interpolated from linear regression of dose $\sim C_{\max }$ based on $\log$-transformed data $\left[\right.$ ie, $\log ($ dose $\left.) \sim \log \left(C_{\max }\right)\right]$ because the clinical therapeutic dose $(300 \mathrm{mg})$ was not conducted in the Phase 1 study (304801-CS1 CSR).

$\mathrm{MD}$, multiple dose; CI, confidence interval. respectively. On average, the peak plasma exposure of mipomersen was $\sim 3.8$-fold higher after the IV infusion compared with the SC injection of mipomersen. Results from this study demonstrated that mipomersen had no effects on HR, PR, and QRS interval duration based on both time-matched analyses and

Table 6. Predicted $\Delta \Delta \mathrm{QTCF}$ at the SUPRATHERAPEUtic EXPOSURE $\left(2 \times C_{\text {Max }}\right)$

\begin{tabular}{lclc}
\hline & & \multicolumn{2}{c}{ Predicted $\Delta \Delta Q T c F(\mathrm{~ms})$} \\
\cline { 3 - 4 } Compound & $\begin{array}{c}2 \times C_{\max } \mathrm{a} \\
(\mathrm{ng} / \mathrm{mL})\end{array}$ & Estimate & $\begin{array}{c}\text { Upper two- } \\
\text { sided } 90 \% \mathrm{CI}\end{array}$ \\
\hline ISIS 301012 $^{\mathrm{b}}$ & 10,320 & -5.60 & -2.22 \\
ISIS 304801 $^{\mathrm{c}}$ & 13,752 & -7.92 & 1.85 \\
ISIS 505358 $^{2}$ & 15,408 & -0.673 & 7.29 \\
ISIS 463588 & 10,304 & -8.66 & -0.24 \\
ISIS 416858 & 22,800 & -7.77 & 0.29 \\
ISIS 420915 & 14,180 & -1.06 & 5.56 \\
ISIS 404173 & 5,800 & -8.73 & 0.080 \\
ISIS 329993 & 9,952 & -3.30 & -2.23 \\
ISIS 546254 & 21,200 & -7.08 & 1.64 \\
ISIS 449884 & 3,240 & 1.01 & 5.42 \\
\hline
\end{tabular}

${ }^{\mathrm{a}} C_{\max }$ is the observed geometric mean $C_{\max }$ following the last dose in the multiple-dose cohort of therapeutic dose level for all studies except noted.

${ }^{\mathrm{b}} C_{\max }$ was obtained from Li et al. [21].

${ }^{\mathrm{c}} C_{\max }$ was interpolated from linear regression of dose $\sim C_{\max }$ based on $\log$-transformed data [ie, $\log ($ dose $\left.) \sim \log \left(C_{\max }\right)\right]$ because the clinical therapeutic dose $(300 \mathrm{mg})$ was not conducted in the Phase 1 study (304801-CS1 CSR). 
ER analysis. There were no new clinically relevant morphological changes. Finally, a recent publication on custirsen, a 413-4 2'-MOE gapmer ASO, showed no effect on QT intervals based on PK/QT data in a Phase 1 dose-escalation study with dose up to $640 \mathrm{mg}$ administered via 2-h IV infusion and plasma concentrations up to $90,000 \mathrm{ng} / \mathrm{mL}$ [13].

The data package on the lack of QT effect of $2^{\prime}$-MOE ASOs as demonstrated in 10 Phase 1 studies conducted by Ionis Pharmaceuticals, a TQT study conducted by Genzyme Corporation [13], and a study conducted by Teva Pharmaceuticals [13], was overwhelmingly consistent. Because of the similarities of 2'-MOE ASOs in terms of physicochemical properties and PK profiles, a lack of effect on QT prolongation in humans, as demonstrated by a TQT study and ER analysis for a group of 10 similar 2'-MOE ASOs as well as supporting data from the literature [13], can be generalized to $2^{\prime}$-MOE ASOs of the same chemical class.

We recognize that there are some limitations in the data collection of these Phase 1 studies that did not meet the recently published ICH E14 Guideline Q\&As (R3) 2015 (ICH 2015) in ER analysis. First, only a single ECG measurement was collected at each time point in these Phase 1 studies, and thus, the data could be prone to have outliers. However, evaluation of the data showed that only two ECG measurements could be considered as outliers from these 10 Phase 1 studies. Therefore, the quality of the overall ECG data was considered to be reliable. Second, the collection time point for ECG measurement was limited. Nonetheless, all the studies included the collection times at or near $C_{\max }$. In addition, two of the ten studies included IV infusion in addition to SC administration, with the highest plasma concentrations observed exceeding $4 \times C_{\max }$ of the therapeutic dose for all the ten 2'-MOE ASOs evaluated. Finally, time-matched mean placebo correction was used in the " $\Delta \Delta$ " approach rather than within-subject placebo treatment correction because the subjects in these Phase 1 studies did not cross over to receive active or placebo treatment as those in a TQT study. Although the Phase 1 QT data for a given compound are limited, the pooled QT data from multiple compounds and studies are compelling, and results are convincing that ASOs do not cause QT prolongation.

\section{Conclusions}

None of the ten 2'-MOE ASOs studied in Phase 1 studies at doses up to $400 \mathrm{mg}$ SC or $600 \mathrm{mg}$ IV for 4 weeks showed an effect on cardiac repolarization, and no positive correlation between QTcF and plasma concentrations was observed. The lack of effect on QT intervals with ASO treatment was further confirmed in a TQT study with mipomersen, one of the 2'MOE ASOs evaluated. These results from ten $2^{\prime}$-MOE ASOs suggest a lack of effect on QT intervals with ten $2^{\prime}$-MOE ASOs, as a class in healthy subjects and the ER analysis of QT data in Phase 1 dose-escalation studies can be as informative as TQT studies advocated by experts in the field.

\section{Acknowledgments}

The authors thank Wei Cheng, Matt Buck, Seung Chun, Drs. Brett Monia, Elizabeth Ackermann; Brenda Baker and Walter Singleton for their scientific discussion and critical review of the article. Finally, this article would not have been possible without the administrative support provided by Robert Saunders, for which they are grateful.

\section{Author Disclosure Statement}

R.Z.Y., R.G., R.S.G., S.H., S.H., and Y.W. are all employees of Ionis Pharmaceuticals.

\section{References}

1. Crooke ST. (2004). Antisense strategies. Curr Mol Med 4: 465-487.

2. Bennett CF and EE Swayze. (2010). RNA targeting therapeutics: molecular mechanisms of antisense oligonucleotides as a therapeutic platform. Annu Rev Pharmacol Toxicol 50:259-293.

3. Geary RS, T Ushiro-Watanabe, L Truong, SM Freier, EA Lesnik, NB Sioufi, H Sasmor, M Manoharan and AA Levin. (2001). Pharmacokinetic properties of 2'-O-(2-methoxyethyl)modified oligonucleotide analogs in rats. J Pharmacol Exp Ther 296:890-897.

4. Geary RS, RZ Yu, T Watanabe, SP Henry, GE Hardee, A Chappell, J Matson, H Sasmor, L Cummins and AA Levin. (2003). Pharmacokinetics of a tumor necrosis factor-alpha phosphorothioate 2'-O-(2-methoxyethyl) modified antisense oligonucleotide: comparison across species. Drug Metab Dispos 31:1419-1428.

5. Geary RS, D Norris, R Yu and CF Bennett. (2015). Pharmacokinetics, biodistribution and cell uptake of antisense oligonucleotides. Adv Drug Deliv Rev 87:46-51.

6. Yu RZ, T-W Kim, A Hong, TA Watanabe, HJ Gaus and RS Geary. (2007). Cross-species pharmacokinetic comparison from mouse to man of a second generation antisense oligonucleotide ISIS 301012, targeting human ApoB-100. Drug Metab Dispos 35:460-468.

7. Grundy JS, RZ Yu, RS Geary, AA Levin, S Zhao, A Keyhani and G Piccirilli. (2002). Comparative single-dose disposition of radiolabeled ISIS 104838 and ISIS 113715 in rat. In Annual Meeting of Pharmaceutical Scientists. Toronto, Canada.

8. Crooke ST, BF Baker, TJ Kwoh, W Cheng, DJ Schulz, S Xia, N Salgado, HH Bui, CE Hart, et al. (2016). Integrated safety assessment of 2'-O-methoxyethyl chimeric antisense oligonucleotides in nonhuman primates and healthy human volunteers. Mol Ther 24:1771-1782.

9. Yu RZ, RS Geary, JD Flaim, GC Riley, DL Tribble, AA Vanvliet and MK Wedel. (2009). Lack of pharmacokinetic interaction of mipomersen sodium (ISIS 301012), a 2'-O-methoxyethyl modified antisense oligonucleotide targeting apolipoprotein B-100 messenger RNA, with simvastatin and ezetimibe. Clin Pharmacokinet 48: 39-50.

10. Yu RZ, MS Warren, T Watanabe, B Nichols, M Jahic, J Huang, J Burkey, RS Geary, SP Henry and Y Wang. (2016). Lack of interactions between an antisense oligonucleotide with 2'-O-(2-methoxyethyl) modifications and major drug transporters. Nucleic Acid Ther 26:111117.

11. Geary RS, JD Bradley, T Watanabe, Y Kwon, M Wedel, JJ Van Lier and AA Vanvliet. (2006). Lack of pharmacokinetic interaction for ISIS 113715, a 2'O-methoxyethyl modified antisense oligonucleotide targeting protein tyrosine phosphatase $1 \mathrm{~B}$ messenger RNA, with oral antidiabetic compounds metformin, glipizide or rosiglitazone. Clin Pharmacokinet 45:789-801.

12. Kim TW, KS Kim, JW Seo, SY Park and SP Henry. (2014). Antisense oligonucleotides on neurobehavior, respiratory, and cardiovascular function, and hERG channel current studies. J Pharmacol Toxicol Methods 69:49-60. 
13. Rabinovich-Guilatt L, A Elgart, L Erisson, SK Willsie, S Tessler, O Barnett-Griness, A Pande and O Spiegelstein. (2015). Impact of dosing regimen of custirsen, an antisense oligonucleotide, on safety, tolerability and cardiac repolarization in healthy subjects. Br J Clin Pharmacol 80:436-445.

14. Yu RZ, R Gunawan, Z Li, RS Mittleman, A Mahmood, JS Grundy, W Singleton, R Geary and Y Wang. (2016). No effect on QT intervals of mipomersen, a 2'-O-methoxyethyl modified antisense oligonucleotide targeting ApoB-100 mRNA, in a phase I dose escalation placebo-controlled study, and confirmed by a thorough QT (tQT) study, in healthy subjects. Eur J Clin Pharmacol 72:267-275.

15. Darpo B, C Garnett, J Keirns and N Stockbridge. (2015). Implications of the IQ-CSRC prospective study: time to revise ICH E14. Drug Saf 38:773-780.

16. Darpo B, N Sarapa, C Garnett, C Benson, C Dota, G Ferber, V Jarugula, L Johannesen, J Keirns, et al. (2014). The IQ-CSRC prospective clinical Phase 1 study: "Can early QT assessment using exposure response analysis replace the thorough QT study?" Ann Noninvasive Electrocardiol 19:70-81.

17. ICH. (2015). Final Concept Paper E14 Q\&As (R3), Revision of ICH E14 Q\&As (R2). (Endorsed by the ICH Steering Committee. www.ich.org/fileadmin/Public_Web_ Site/ICH_Products/Guidelines/Efficacy/E14/E14_Q_A_R3_ Final_Concept_Paper_9June_2015.pdf

18. Yu RZ, B Baker, A Chappel, RS Geary, E Chueng and AA Levin. (2002). Development of an ultrasensitive noncompetitive hybridization-ligation enzyme-linked immunosor- bent assay for the determination of phosphorothioate oligodeoxynucleotide in plasma. Anal Biochem 304:19-25.

19. OECD. (1998). Principles of Good Laboratory Practice. Organisation for Economic Cooperation and Development, Paris, France.

20. Sewell LK, RS Geary, BF Baker, JM Glover, TGK Mant, RZ Yu, JA Tami and AF Dorr. (2002). Phase I trial of ISIS 104838, a 2'-methoxyethyl modified antisense oligonucleotide targeting tumor necrosis factor-alpha. J Pharmacol Exp Ther 303:1334-1343.

21. Li Z, ML Hard, G Andersen, G Pabst, G Wagener, T Singh, W Chin, K. Culm-Merdek, I Boltje and LL Von Moltke. (2014). Pharmacokinetics, safety and tolerability of mipomersen in healthy Japanese volunteers and comparison with Western subjects. Int J Clin Pharmacol Ther 52:314-320.

Address correspondence to: Rosie Z. Yu, PhD

Department of Pharmacokinetics and Clinical Pharmacology

Ionis Pharmaceuticals, Inc. 2855 Gazelle Court Carlsbad, CA 92010

E-mail: ryu@ionisph.com

Received for publication April 25, 2017; accepted after revision July 6, 2017. 